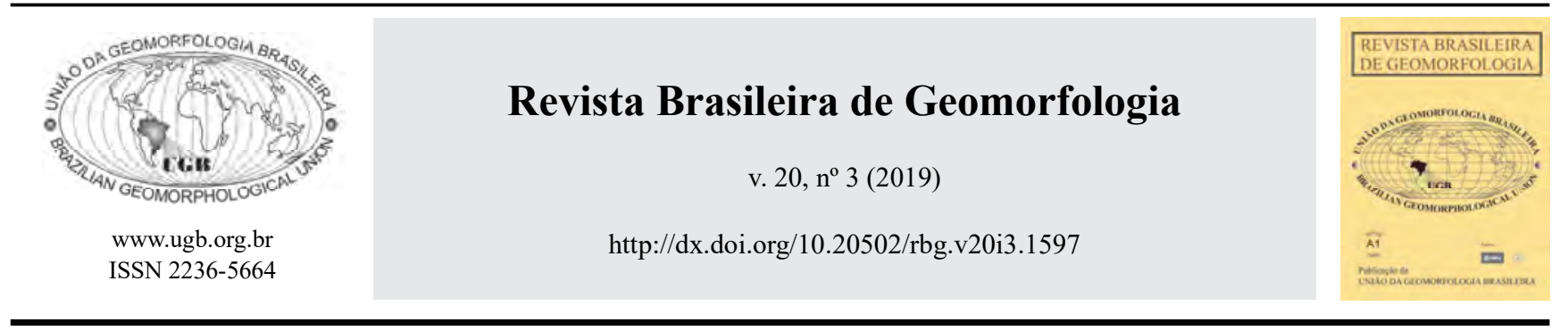

\title{
MORFOLOGIAS FLUVIAIS EM AMBIENTE SEMIÁRIDO: QUESTÕES TEÓRICAS APLICADAS A UM ESTUDO DE CASO
}

\section{FLUVIAL MORPHOLOGIES IN SEMIARID ENVIRONMENT: THEORETICAL ISSUES APPLIED TO A CASE STUDY}

\author{
Kleber Carvalho Lima \\ Departamento de Geografia, Campus Rio Claro, Universidade Estadual Paulista "Júlio de Mesquita Filho" \\ Avenida 24 - A, 1515, Rio Claro, São Paulo. CEP: 13506-900. Brasil \\ ORCID: 0000-0002-9468-2473 \\ E-mail: klebercarvalho.two@gmail.com \\ Cenira Maria Lupinacci \\ Departamento de Planejamento Territorial e Geoprocessamento, Campus Rio Claro, Universidade Estadual Paulista "Júlio de Mesquita Filho" \\ Avenida 24 - A, 1515, Rio Claro, São Paulo. CEP: 13506-900. Brasil \\ ORCID: 0000-0002-4732-1421 \\ E-mail: cenira.lupinacci@unesp.br
}

\begin{tabular}{l} 
Informações sobre o Artigo \\
\hline Recebido (Received): \\
21/02/2019 \\
Aceito (Accepted): \\
25/05/2019
\end{tabular}

Palavras-chave:

Descontinuidade de Canais; Fluxos Efêmeros; Geomorfologia Fluvial.

\section{Keywords:}

Discontinuity Channels; Ephemeral streams; Fluvial Geomorphology.

\begin{abstract}
Resumo:
Morfologias fluviais associadas a drenagens efêmeras são pouco conhecidas na literatura geomorfológica nacional, onde pesquisas sobre o tema abordaram diferentes aspectos da dinâmica fluvial. No estudo de caso do riacho da Cruz, semiárido da Bahia, discutiram-se definições e avaliou-se a empregabilidade de termos geomorfológicos utilizados na bibliografia nacional e internacional relativos ao cenário local, no sentido de produzir conhecimento sobre aspectos ainda não explorados na literatura brasileira para o semiárido. Foram discutidas expressões relacionadas a formas identificadas na área em estudo, como canal de drenagem, cabeceiras de drenagem, discontinuity channel, sheetflood zone, headcut, floodout, terminal fan e channel fan. A partir de trabalhos de campo, de dados granulométricos e das discussões teóricas, parte dos vocábulos foram adaptados ou adotados integralmente, assim como foram elaboradas expressões próprias. Avaliou-se, dessa maneira, que o emprego de terminologias deve ser realizado com precaução, no sentido de adapta-las aos contextos pesquisados, além disso, deve aproximar-se da produção geomorfológica de caráter internacional.
\end{abstract}

\section{Abstract:}

Fluvial morphologies related to ephemeral drainage are barely known in Brazilian geomorphological literature, where the researches about the theme has addressed different aspects of fluvial dynamics. In the riacho 
da Cruz case study - Bahia State semi-arid - the employability of geomorphological terms used in the national and international bibliography to the local scenario were discussed in order to produce knowledge about aspects not explored in the Brazilian semiarid literature yet. The expressions related to fluvial forms identified that were discussed are drainage channel, discontinuity channel, sheetflood zone, headcut, floodout, terminal fan and channel fan. From field studies, particle size distribution (PSD) analysis and theoretical discussions, some expressions from literature were adopted integrally or adapted, in addition to new expressions elaborated. Therefore, were evaluated that the use of terminologies should be done with wariness, in order to adapt them to the researched contexts, and it must be connected to the international geomorphological literature.

\section{Introdução}

Na bibliografia geomorfológica nacional é premente o desenvolvimento de uma literatura específica, voltada para os processos de elaboração do relevo sob atuação do clima semiárido, especialmente no que se refere aos temas relacionados às dinâmicas fluviais nesse tipo de ambiente, como já apontaram autores como Souza e Almeida (2015) e Cavalcante (2018). Embora sejam registradas na literatura brasileira produções que discutem processos e formas fluviais no contexto do sertão semiárido, o tema precisa de discussões mais amplas, no sentido de organizar sistematicamente o conhecimento a respeito das dinâmicas que ocorrem a nível de detalhe nos canais de drenagem, particularmente nos canais com fluxos efêmeros.

Contribuições significativas foram produzidas através da abordagem de diferentes aspectos da dinâmica fluvial no semiárido. Corrêa (2011) discorreu a respeito da morfogênese semiárida sob o efeito de eventos climáticos de alta magnitude na bacia do riacho Salgado, sertão pernambucano. Azambuja (2012) pesquisou depósitos fluviais elaborados no Quaternário, apresentando aspectos dos processos atuais de erosão e sedimentação nos canais de drenagem da bacia do riacho Salgado, Pernambuco. Cantalice et al. (2013) investigaram a relação entre a carga de sedimentos em suspensão e a carga de leito do canal de drenagem efêmero do Rio Exu (Pernambuco) e concluíram que a descarga possui características de transporte de sedimentos semelhantes a canais efêmeros de desertos.

Souza e Almeida (2015) realizaram o levantamento teórico dos principais conceitos relacionados aos sistemas fluviais de regiões secas, focando no semiárido brasileiro. Com base em Graf (1988), os autores traduziram para a literatura de língua portuguesa os tipos de inundações comuns nas regiões secas, trazendo contribuições significativas para o conhecimento do tema na literatura nacional. Cavalcante (2018), a partir do estudo do Rio Jaguaribe, Ceará, discutiu elementos conceituais relacionados à morfodinâmica fluvial, a exemplo da descarga, vazão, padrões de drenagem, dentre outros, no contexto do semiárido do Brasil. Andrade e Maia (2018) mensuraram processos erosivos nas margens do rio Jaguaribe (Ceará) e concluíram que, mesmo em período com médias pluviométricas abaixo da média histórica, as precipitações foram a principal condicionante responsável pela erosão marginal.

Considerando o contexto de drenagens efêmeras sob dinâmicas fluviais semiáridas, propõe-se nesse artigo discutir questões terminológicas/conceituais de processos e formas no canal de drenagem, a partir da bibliografia nacional e internacional, e analisar a sua aplicabilidade em uma bacia hidrográfica do semiárido da Bahia. Objetiva-se, ainda, aproximar a bibliografia internacional sobre o tema ao contexto do semiárido brasileiro, avaliando a empregabilidade de termos geomorfológicos ao cenário nacional.

\section{2. Área de estudo}

A bacia hidrográfica do riacho da Cruz (BHRC) está localizada na porção nordeste do semiárido da Bahia (figura 1), apresenta área de $65,9 \mathrm{~km}^{2}$, e se desenvolveu sobre o domínio estrutural do Complexo Santaluz. Formado no Arqueano Médio Inferior $(>3,0$ $\mathrm{Ga})$, o complexo integra o Bloco Serrinha, localmente composto por gnaisses bandados, gnaisses a granadas $\mathrm{e}$ níveis de rochas calcissilicáticas; ortognaisses granodioríticos de textura augen; e gnaisses migmatizados (figura 1). Associadas ao Complexo Santaluz ocorrem intrusões do Proterozóico Inferior, compostas por sienitos, monzogranitos, sinogranitos e monzonitos (CPRM, 1989). Do ponto de vista estrutural, a área é caracterizada pela ocorrência de falhas, fraturas e lineamentos estruturais com orientação preferencial NO-SE. 


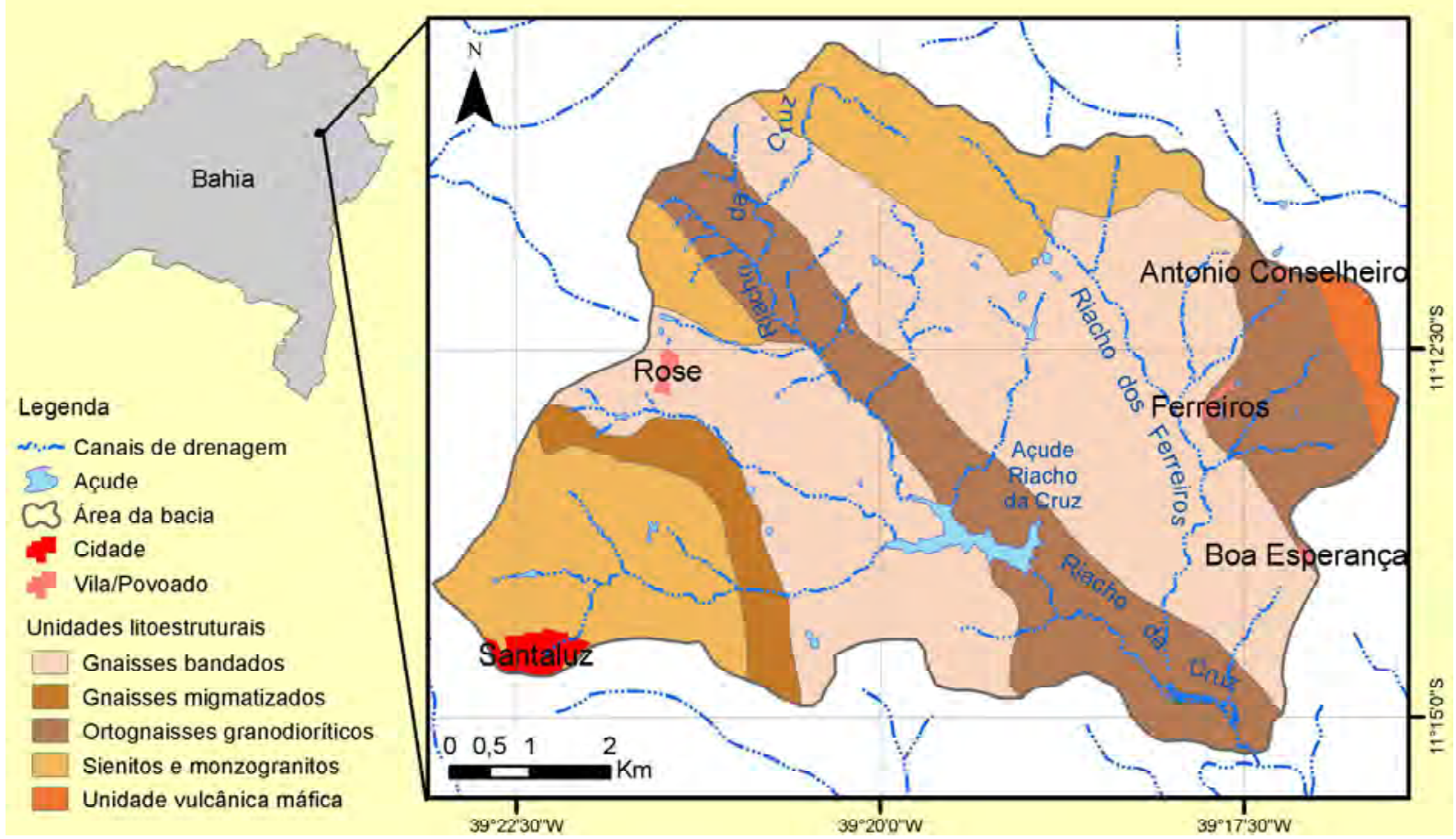

Figura 1-Mapa de localização com unidades litológicas da bacia hidrográfica do riacho da Cruz (Bahia). Fonte: base de dados da CPRM (1989).

Sobre a litologia antiga, de alta resistência à erosão, atua localmente o clima Semiárido do tipo Dd' A' segundo a classificação de Tornthwaite e Matther, com temperatura média anual de $24^{\circ} \mathrm{C}$ e pluviosidade média anual de 537,9 mm (SEI, 1999). O índice de evaporação real, obtido por meio de dados da Estação Santaluz, apresentou valor de 537,9mm para o período entre 1943 e 1983. Em decorrência disso, o excedente hídrico foi negativo na BHRC $(0,0 \mathrm{~mm})$ e a taxa de deficiência hídrica foi de 715, $4 \mathrm{~mm}$. O índice de aridez, considerado como reflexo direto da deficiência hídrica, apresentou valor de 57,1 (SEI, 1999).

De acordo com o climograma local (figura 2), o período com maiores volumes de chuva está entre os meses de novembro e março ( $60 \mathrm{~mm})$ e o período mais seco entre julho e outubro ( $\sim 20 \mathrm{~mm})$. Entretanto, a bacia é marcada pela irregularidade e escassez de chuvas com estiagens constantes, especialmente nos períodos de atuação de $E l$ Niño. Podem ocorrer, nos períodos secos, precipitações ocasionais em regime de torrente, típicas de regiões secas.

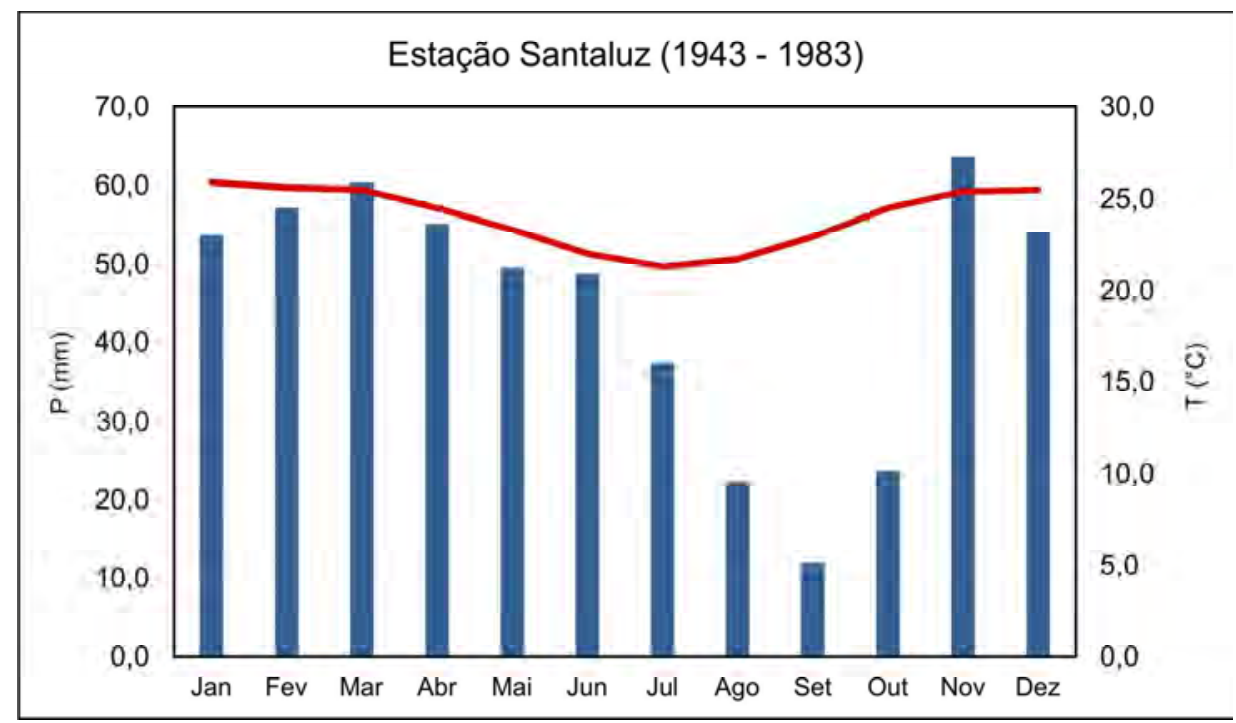

Figura 2 - Climograma da Estação Santaluz (1943 a 1983). Fonte: base de dados da SEI (1999). 
Durante as chuvas de caráter torrencial, ocorre a "lavagem" da superfície através do escoamento superficial que, por sua vez, adquire força suficiente para transportar o material originado com a desagregação das rochas. Dessa maneira, considera-se essa modalidade de escoamento como um dos agentes mais eficazes na promoção da esculturação da superfície semiárida. A combinação da litologia e estrutura com a semiaridez climática favoreceu o desenvolvimento regional de uma vasta superfície aplainada, inserida na Depressão Sertaneja, composta por níveis dissecados e conservados de pedimentos e inselbergues. Sobre os pedimentos se desenvolveu a rede de drenagem, composta por canais de drenagem efêmeros que apresentam fluxo hídrico apenas durante e imediatamente após as chuvas torrenciais.

\section{Materiais e métodos}

O mapeamento das drenagens na área em estudo foi realizado em escala 1:3.000, a partir de imagens orbitais Digital Globe de 2004, disponíveis no $\operatorname{Arc} G I S \AA$, desde que o usuário esteja conectado à internet. Uma vez que não é possível o acesso direto às imagens históricas dessa fonte via SIG, foram utilizadas imagens de outros anos em diferentes épocas, disponibilizadas pelo Google Earth ${ }^{\circledR}$. As imagens foram salvas e georreferenciadas no $\mathrm{Ar}$ $c G I S ®$. Observa-se que para a área em estudo, as imagens possuem resolução espacial suficiente para a representação das feições fluviais em nível de detalhe.

As simbologias de representação cartográfica foram adaptadas de manuais de mapeamento geomorfológico (TRICART, 1965; VERSTAPPEN e ZUIDAM, 1975; IBGE, 2009), no sentido de abordarem os atributos e os processos responsáveis pela elaboração dos canais de drenagem e formas aluviais. Os símbolos foram caracterizados na cor azul, e os vetores representam o comportamento da água nos canais de drenagem e o trabalho do fluxo fluvial. Os conflitos entre feições que se assemelharam a canais de drenagem desconfinados e a estradas/caminhos de pedestres, gerados na fase de interpretação das imagens, foram solucionados nos trabalhos de campo, de acordo com as orientações propostas por Lima e Cunha (2014).

Em campo foram identificadas feições de detalhe inseridas no leito, a exemplo de barras laterais, barras centrais e leques. As feições foram descritas por meio de fotografias e seções transversais ao canal foram realizadas com o auxílio de GPS (Global Positioning System), trena digital, fita métrica e barra graduada com 10 intervalos de 20 centímetros. Esses dados permitiram a elaboração de mapas de campo com a representação de feições internas ao canal de drenagem, não identificáveis nas imagens orbitais.

Com vistas à compreensão das dinâmicas atuais de transporte e deposição dos fluxos efêmeros, foram amostrados sedimentos que compõem as formas inseridas no canal para análise granulométrica. As amostras foram tomadas com profundidade entre 0 e $20 \mathrm{~cm}$ para reconhecimento das frações cascalho, areia, silte e argila. A realização da análise granulométrica ocorreu no Laboratório para Análise de Formações Superficiais (LAFS) da UNESP/Rio Claro, adotando-se o método da Pipeta IAC (CAMARGO et al., 2009) cuja rotina foi realizada de acordo com os procedimentos operacionais do LAFS.

\section{Resultados e discussão}

A partir dos dados de campo, de laboratório e da bibliografia nacional e internacional, foram realizadas discussões sobre aspectos morfológicos de feições comuns em regiões semiáridas como a área em estudo, porém pouco conhecidas na literatura geomorfológica brasileira: discontinuity channels, sheetflood zone, headcut, floodout, terminal fan e channel fan. De maneira complementar, abordou-se termos sob o viés do ambiente semiárido, como canal de drenagem, drenagem efêmera, cabeceira de drenagem, barra lateral e barra central.

\subsection{Tipologia de canal}

$\mathrm{Na}$ BHRC foram identificados 35 canais que compõem uma rede de drenagem instalada predominantemente sobre superfície de erosão plana (0 a 5\% de declividade). São canais que apresentam fluxos esporádicos de baixa energia, com modificações pontuais do potencial erosivo nos trechos onde há mudanças litológicas, estruturais e topográficas.

Do ponto de vista morfológico, o canal de drenagem é composto primariamente por um leito e pelas margens que o definem lateralmente, sendo responsável pelo escoamento de água fluvial (GUERRA e GUERRA, 2011). Christofoletti (1980) definiu rio como "uma corrente contínua de água, mais ou menos caudalosa, que deságua noutra, no mar ou lago" (op cit, pg. 65), 
onde o caráter canalizado do fluxo é fundamental para a constituição de um rio (STEVAUX e LATRUBESSE, 2017). O termo rio é comum na literatura nacional, sendo empregado especialmente no cenário quente e úmido, predominante no país, embora, por vezes, seja utilizado para o ambiente quente e seco. Com base na definição apresentada por Christofoletti (1980), considera-se o emprego do vocábulo inadequado para o semiárido, sob a óptica dos canais com escoamento efêmero.

Como canal de drenagem efêmero definem-se aqueles cujo fluxo hídrico ocupa o leito episodicamente, durante e logo após os eventos de precipitação, permanecendo secos na maior parte do tempo (GRAF, 1988). Apesar do caráter episódico, os fluxos efêmeros executam as mesmas funções hidrológicas que os fluxos perenes, pois movem água, sedimentos e nutrientes; recarregam os lençóis subterrâneos; proporcionam a conectividade física e biológica no habitat para espécies locais; e podem suportam grande parte da biodiversidade em regiões secas (VYVERBERG, 2010).

É comum na área de estudo a ocorrência de canais com margens rasas, tornando-os imperceptíveis, tanto em imagens orbitais quanto no próprio terreno. As margens do canal de drenagem podem ser tão suaves a ponto de serem confundidos com estradas não pavimentadas ou caminhos de pedestre. Razões para isso estão no baixo potencial de incisão do fluxo, devido principalmente ao escoamento hídrico esporádico, à resistência do material à erosão e à baixa declividade do terreno (GRAF, 1988; TOOTH e NANSON, 2011; GOUDIE, 2013).

Dessa maneira, ocorrem canais confinados e desconfinados, com larguras maiores que as profundidades. Os canais confinados (figura 3) possuem leito bem definido, com relativa incisão do canal e formação de talvegue, com maior energia do fluxo hídrico quando da sua ocorrência. Em alguns trechos, é comum o preenchimento do leito por sedimentos aluviais, originários da carga de fundo, além de sedimentos transportados pelo escoamento superficial nos pedimentos (figura 3 a). Nos trechos sinuosos do riacho da Cruz, próximos à confluência com o rio Bom Sucesso, ocorre alternância erosiva entre as margens, com presença de fragmentos estreitos de baixos terraços (figura $3 \mathrm{~b}$ ) nas margens convexas.

Os canais desconfinados (figura 4) possuem margens rasas e leitos mal definidos ou não definidos. Em geral, ocorrem nas áreas de topografia plana com litologias mais resistentes, onde a baixa energia dos fluxos reduz o potencial erosivo de entalhamento do talvegue. Assim, ocorrem na BHRC canais desconfinados com preenchimento do leito e incisão incipiente do talvegue; e canais cujas margens são indefinidas, com acréscimos laterais significativos de sedimentos.

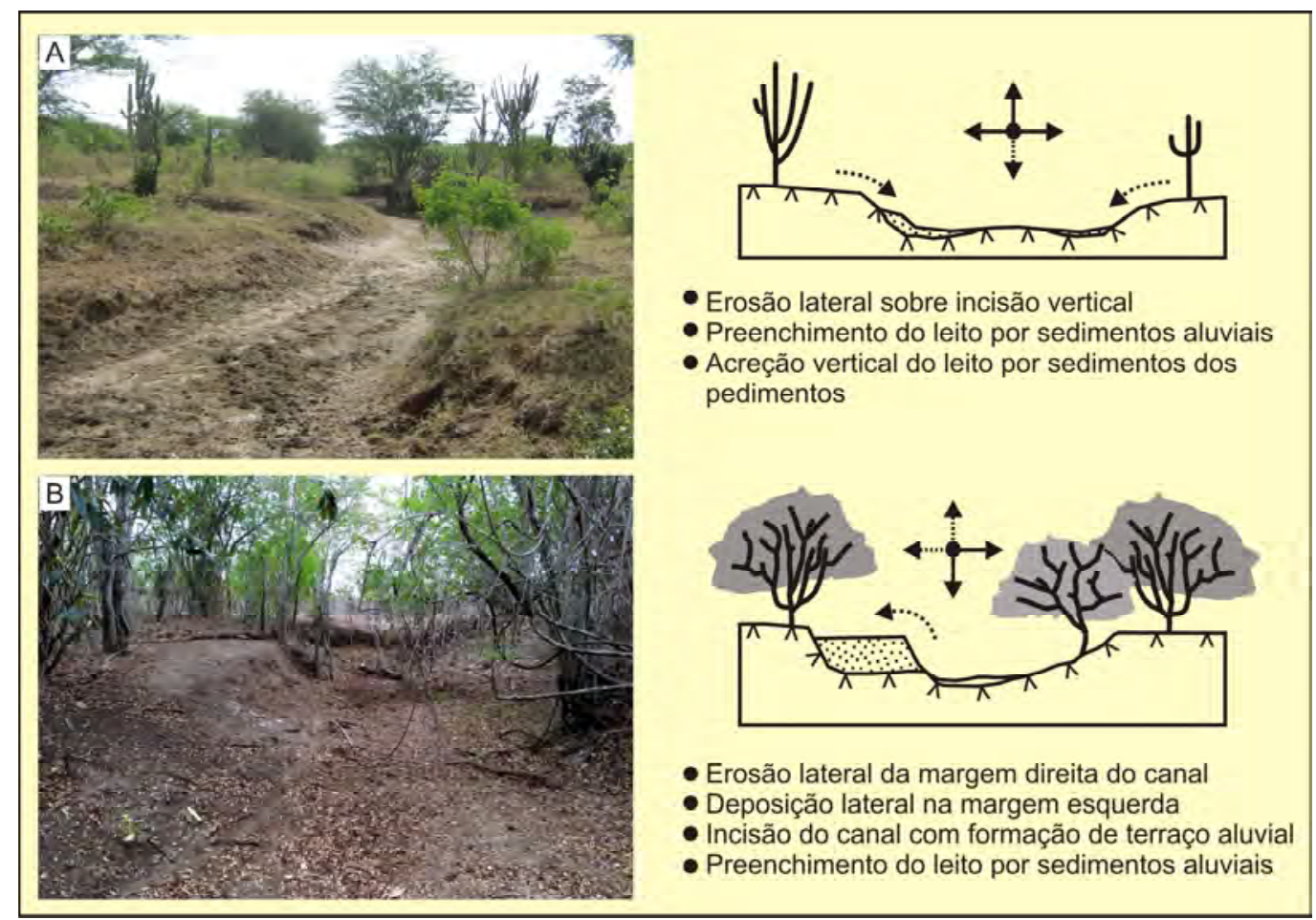

Figura 3 - Esquema representativo de canais confinados na BHRC: (a) canal confinado com predomínio de erosão lateral e; (b) canal confinado com acreção lateral e relativa incisão do canal. 


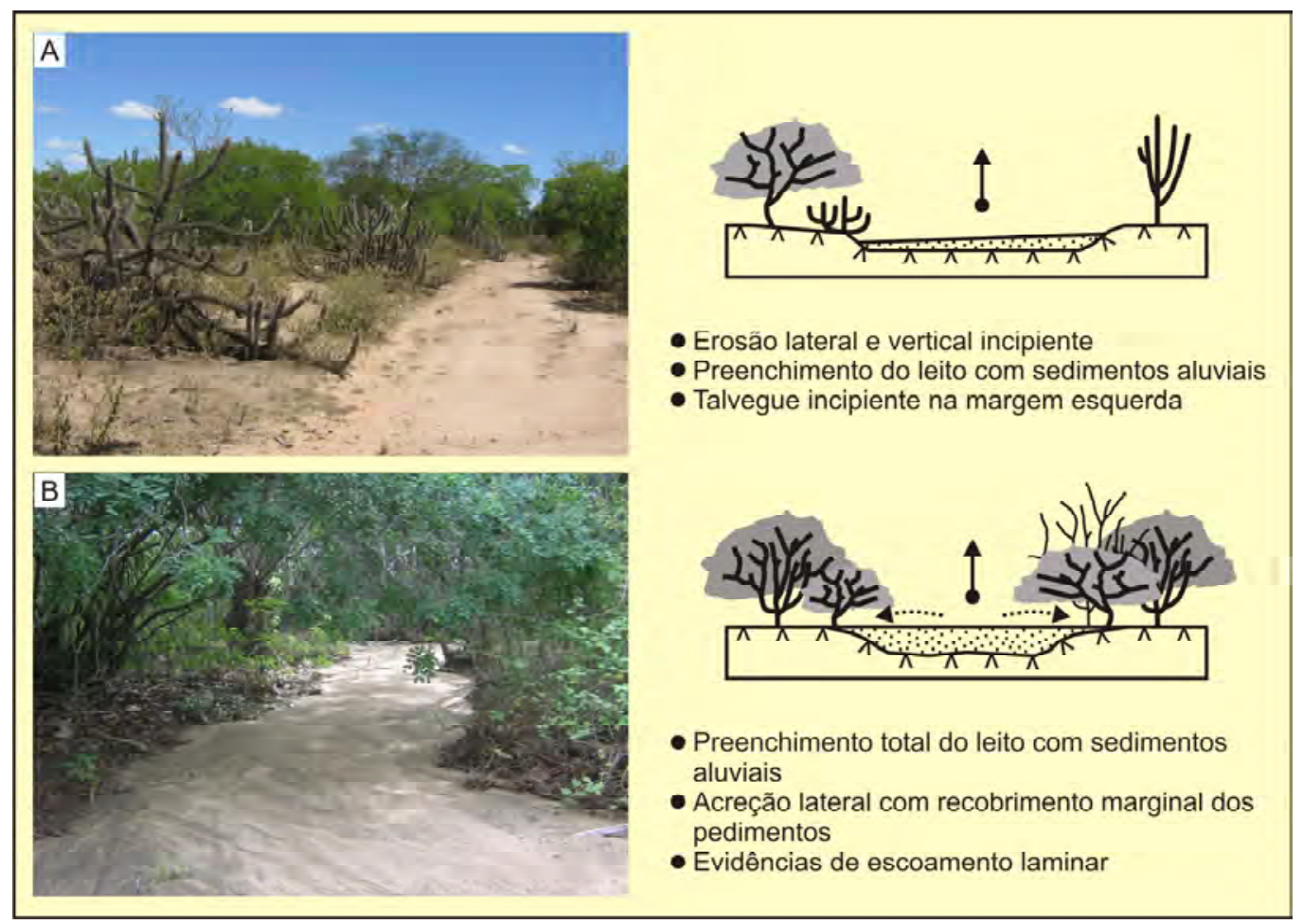

Figura 4 - Esquema representativo de canais desconfinados na BHRC: (a) leito plano com incisão incipiente do talvegue e; (b) trecho de leito preenchido por sedimentos aluviais sem talvegue definido.

Vyverberg (2010) observou que, se existem evidências físicas e biológicas da ocorrência de água no canal e se o mínimo grau de confinamento pode ser identificado, a linha de fluxo (talvegue) definirá o canal de drenagem. Nesse sentido, considera-se que os segmentos de drenagem com características semelhantes às apresentadas na figura $4 \mathrm{~b}$, podem ser considerados como canais de drenagem, pois mesmo que o mínimo grau de confinamento não seja claramente estabelecido, evidências físicas (linhas de fluxo nos sedimentos) e biológicas (vegetação às margens) estão presentes.

Ao longo do riacho da Cruz, ocorrem trechos onde o canal não é nítido em imagens orbitais, formando áreas de espraiamento de sedimentos em forma de leque que se alternam com trechos onde o leito é definido, predominando processos erosivos. Trata-se de uma sequência interposta de leito confinado e desconfinado. $\mathrm{Na}$ literatura geomorfológica internacional o termo descontinuidade de canais (discontinuity channels) é frequentemente utilizado no estudo de redes de drenagem que apresentam características semelhantes e expressa a complexidade inerente aos sistemas fluviais de regiões secas, especificamente aos fluxos efêmeros.

Em pesquisas desenvolvidas no oeste semiárido dos EUA, Schumm e Hadley (1957); Patton e Schumm (1975) identificaram e avaliaram processos em sistemas de drenagem, onde fizeram uso do termo descontinuidade para os canais que apresentaram, alternadamente, trechos deposicionais e erosivos ao longo de um mesmo segmento. Nessa mesma perspectiva, Bull (1997) ao pesquisar o padrão sequencial de trechos confinados e não confinados em canais de drenagem semiáridos, afirmou que as zonas de agradação e degradação de canais descontínuos refletem primariamente o aspecto de desequilíbrio dos fluxos efêmeros.

Em esquema representativo, Field (2001) apresentou a sequência alternada entre zonas de inundação e canal situados em leques aluviais do sudoeste do Arizona (figura 5). A sequência apresenta trechos com o predomínio de processos deposicionais no leito (depositional channel) e os trechos erosivos (erosional channel), intercalados por uma zona de inundação denominada de sheetflood zone. Posteriormente, Field e Lichvar (2007) e Vyverberg (2010) aplicaram a mesma divisão para sistemas fluviais efêmeros descontínuos situados em diversas áreas planas do oeste árido e semiárido dos EUA. 


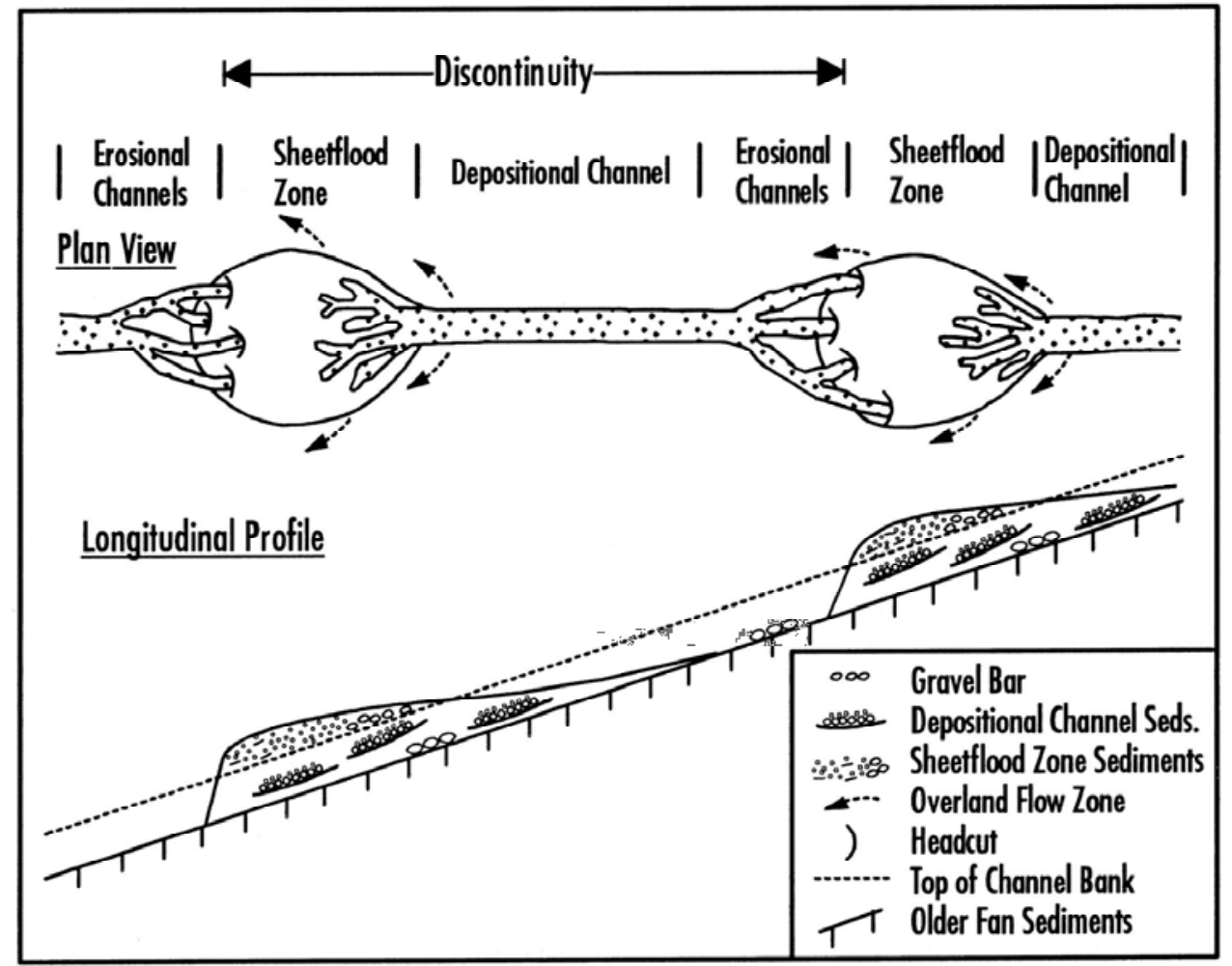

Figura 5 - Esquema representativo de canais efêmeros descontínuos. Fonte: Field (2001, p. 95).

Quando ocorrem fluxos nos canais descontínuos, a energia e a carga de sedimentos são dissipadas nas zonas de inundação, geralmente planas. Os sedimentos são depositados e o fluxo volta a se concentrar nas áreas de headcut, a jusante da zona de inundação (FIELD, 2001), dando origem aos canais erosivos. Os canais erosivos se desenvolvem onde a capacidade de transporte de sedimentos nas zonas de inundação cessa e a água, livre de sedimentos, adquire potencial para erodir a superfície (BULL, 1997). A seqüência completa entre os pontos de incisão é denominada de descontinuidade (SCHUMM e HADLEY, 1957).

A propósito das zonas de inundação (sheetflood zone), Bull (1997) e Vyverberg (2010) as caracterizaram como feições em leque, no âmbito do próprio canal de drenagem. O leque é formado a partir do momento em que o fluxo confinado perde energia, se espraia e deposita os sedimentos. Parte do fluxo infiltra no próprio leito e outra parte forma o escoamento em lençol que, na porção a jusante da zona de inundação, volta a ser confinado. Nessa perspectiva, o termo floodout refere-se a áreas de sedimentação fluvial integrantes de sistemas de drenagem efêmeros no contexto árido e semiárido da Austrália e da África do Sul (TOOTH, 1999; TOOTH et al., 2014). Entretanto, é aplicado tanto para um tipo de processo fluvial quanto para a forma de relevo (GORE et al., 2000).

Como processo de inundação, é reconhecido como um mecanismo primário de aluvionamento que ocorre ao longo de alguns canais de drenagem, geralmente em trechos mais planos. Tooth (1999) destacou que as inundações podem ser do tipo terminais, com a dissipação do fluxo nas áreas planas não confinadas e perda por infiltração, evaporação e/ou pela ausência de fluxos tributários ou; do tipo intermediárias, com a continuidade do fluxo em lençol até o ponto em que retoma o fluxo concentrado e reelabora o canal de drenagem. Do ponto de vista da forma, Brierley e Fryirs (2005) definiram floodout como uma unidade morfológica desenvolvida no leito do canal descontínuo com aspecto lobado ou em forma de leque que se irradia a jusante. São compostos predominantemente por areias (BULL, 1997; TOOTH et al., 2014), podendo acumular material fino na porção frontal e apresentarem perfil convexo.

Em seção representativa no riacho da Cruz (figura 6) é possível visualizar descontinuidades no canal, com as respectivas unidades e setores de análise. No setor 1, a interferência antrópica através da construção de estrada favoreceu a elaboração de um lobo deposicional, imediatamente após o trecho de canal confinado. 
Os sedimentos são retidos nessa área, favorecendo o preenchimento do leito à montante. Como nesse trecho não existem dispositivos de drenagem, a exemplo de ponte ou bueiros, o extravasamento do fluxo para o lado posterior da estrada, em direção à jusante, ocorre apenas em eventos pluviométricos de grande magnitude.

No trecho imediatamente após a estrada não foi possível a identificação do leito nas imagens orbitais, sendo esse considerado como canal desconfinado apenas após a validação em campo. Ocorre a retomada dos processos erosivos após o trecho desconfinado a partir da concentração do escoamento superficial proveniente dos pedimentos e do aumento no gradiente topográfico à jusante. Nas áreas de retomada de erosão, o escoamento volta a ser concentrado em canal confinado até perder gradualmente a energia e formar canais desconfinados e novo lobo deposicional. No caso do lobo deposicional situado entre os setores 2 e 3 (figura 6), sua gênese pode estar relacionada à variável topográfica e à efemeridade do fluxo fluvial.

O setor 3 corresponde a uma nova descontinuidade com retomada de erosão na transição com o setor 2 , sucedido por trecho de canal confinado, canal desconfinado e novo lobo deposicional (figura 6). A energia inicial do fluxo fluvial favorece o desenvolvimento de trechos confinados com margens bem definidas. $\mathrm{Na}$ medida em que a topografia se torna plana e o canal se aproxima de outra estrada, o leito se torna desconfinado e um novo lobo se forma pela retenção de sedimentos adjacente a estrada.

De maneira geral, as amostras de sedimentos tomadas ao longo da descontinuidade do setor 3 (figura 6) revelaram predomínio de classe arenosa seguida de cascalho e porcentagem relativamente pequena de lama. Segundo as características gerais do transporte de sedimentos em canais efêmeros semiáridos (GRAFF, 1988), as amostras apresentaram padrão esperado para esse tipo de ambiente, de onde se infere que o transporte de carga de leito ocorreu por arraste ou saltação, nos momentos de fluxo, com participação pouco significativa do transporte por suspensão. As elevadas perdas na transmissão do fluxo fazem com que a carga de sedimentos aumente em proporções maiores que a descarga, corroborando com a agradação (GORE et al., 2000).

Ao longo do perfil traçado em campo (figura 6), a granulometria das amostras apresentou padrão semelhante, com pequenas variações no grupo das areias (tabela 1). Exceção ocorre com a amostra representativa do trecho confinado do canal, que apresentou elevada porcentagem de cascalho (tabela 1), provavelmente associada à maior competência do fluxo em condições de confinamento do leito. No trecho desconfinado, bem como no lobo deposicional, a predominância de areia, especialmente areia fina (tabela 1), pode indicar a quebra da energia do fluxo e a presença de vegetação.

No contexto do riacho da Cruz, considerou-se inadequada a utilização da expressão zona de inundação no sentido literal da sua tradução do inglês para os lobos deposicionais, devido à ausência de dados sobre o comportamento das cheias, a exemplo de magnitude e frequência do fluxo hídrico. Dessa maneira, optou-se pelo emprego da terminologia leque de canal (figura 6) como um meio de abordar a forma e sua espacialização no sistema fluvial, os aspectos gerais do processo de deposição e a sua composição. Assim, definiu-se leque de canal como forma de relevo desenvolvida por meio do espraiamento de sedimentos grosseiros, predominantemente arenosos, nas áreas planas desconfinadas situadas ao longo de descontinuidades no canal de drenagem. Variáveis antrópicas como obras transversais aos canais (estradas, passagens molhadas e barramentos, dentre outras) podem contribuir para a retenção de sedimentos nos trechos planos.

Sob o aspecto linguistico do termo headcut e a sua tradução para o português, a expressão 'incisão de cabeceira' seria a mais apropriada para o contexto geomorfológico de processos e formas em canais de drenagem. Entretanto, considera-se inadequada para áreas com descontinuidade, semelhantes ao riacho da Cruz (figura 6), no sentido de que o uso do termo cabeceira pode fazer alusão às cabeceiras de drenagem, definidas como áreas onde estão instaladas nascentes ou olhos d'água que originam cursos fluviais (GUERRA e GUERRA, 2011). Segundo esses autores, a tradução de headcut para o português seria cabeceira (topo) de voçoroca (op cit, pág. 97), aplicada a parte mais elevada de uma voçoroca. Da mesma maneira, acredita-se que a tradução utilizada pelos autores é inapropriada para a área em estudo, uma vez que no riacho da Cruz trata-se de degraus topográficos transversais ao canal que favorecem o processo de retomada erosiva. Dessa maneira, acredita-se pertinente a adoção do termo ruptura topográfica. Assume-se, então, o enfoque terminológico tanto para o processo, quanto para a forma. 
Morfologias Fluviais em Ambiente Semiárido: Questões Teóricas Aplicadas a um Estudo de Caso

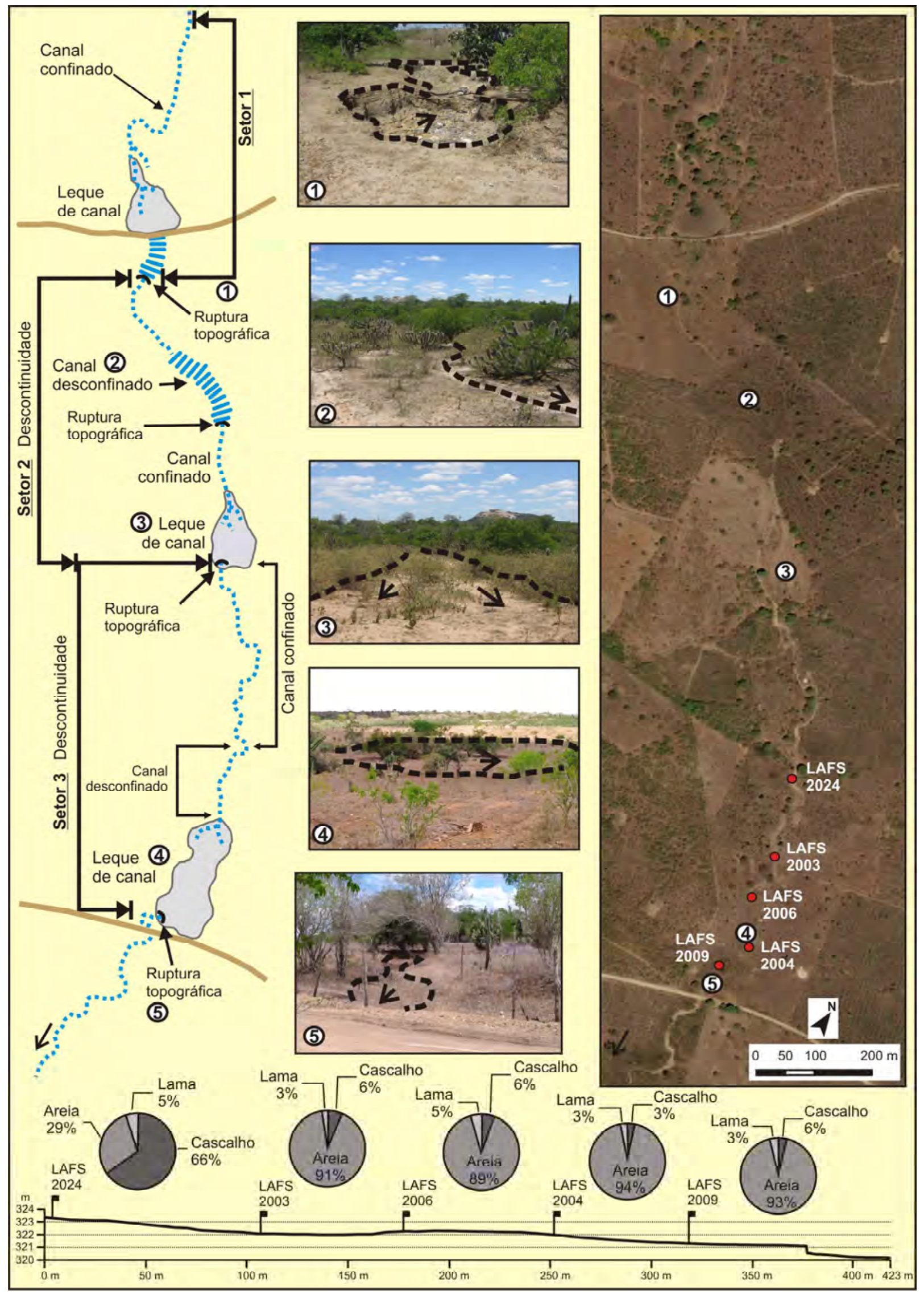

Figura 6 - Seção representativa de descontinuidade no riacho da Cruz, com as feições identificadas em campo e a distribuição espacial da granulometria ao longo do canal. 
Tabela 1: Classes e frações granulométricas das amostras de sedimentos em seção de descontinuidade do riacho da Cruz.

\begin{tabular}{ccccccccccc}
\hline \multicolumn{1}{c}{ Cascalho (\%) } & \multicolumn{7}{c}{ Areia (\%) } & \multicolumn{5}{c}{ Lama (\%) } \\
\cline { 1 - 4 } $\begin{array}{c}\text { Cód. } \\
\text { Amostra }\end{array}$ & $\begin{array}{c}\text { Contexto da } \\
\text { Amostra }\end{array}$ & Fino & $\begin{array}{c}\text { Muito } \\
\text { Fino }\end{array}$ & $\begin{array}{c}\text { Muito } \\
\text { Grossa }\end{array}$ & Grossa & Média & Fina & $\begin{array}{c}\text { Muito } \\
\text { Fina }\end{array}$ & Silte & Argila \\
\hline $\begin{array}{c}\text { LAFS } \\
2024\end{array}$ & $\begin{array}{c}\text { Canal } \\
\text { confinado }\end{array}$ & 56,16 & 9,29 & 0,21 & 0,88 & 3,33 & 9,14 & 15,60 & 5,07 & 0,30 \\
\hline $\begin{array}{c}\text { LAFS } \\
2003\end{array}$ & $\begin{array}{c}\text { Canal } \\
\text { desconfinado }\end{array}$ & 1,75 & 4,10 & 2,66 & 14,64 & 24,38 & 29,81 & 20,04 & 2,55 & 0,08 \\
\hline $\begin{array}{c}\text { LAFS } \\
2004\end{array}$ & Leque de canal & 0,00 & 2,72 & 2,84 & 12,98 & 24,11 & 32,62 & 21,91 & 2,77 & 0,04 \\
\hline $\begin{array}{c}\text { LAFS } \\
2006\end{array}$ & Leque de canal & 1,79 & 3,84 & 2,01 & 15,92 & 23,36 & 30,12 & 18,08 & 4,79 & 0,08 \\
\hline $\begin{array}{c}\text { LAFS } \\
2009\end{array}$ & Leque de canal & 0,00 & 3,65 & 2,26 & 14,92 & 24,10 & 28,56 & 22,91 & 3,52 & 0,08 \\
\hline
\end{tabular}

\subsection{Morfologias de canal}

Selecionou-se, para fins de análise de unidades de relevo no leito dos canais, uma seção situada na confluência entre o riacho dos Ferreiros e o riacho da Cruz, contendo barras deposicionais, talvegue, soleiras e feição em leque (figura 7), conforme discussões seguintes.

No trecho anterior ao leque, o canal apresentou leito confinado com seções transversais ao canal, onde a razão entre largura e profundidade é típica de ambientes secos, sendo que as soleiras evidenciam o baixo potencial de incisão dos fluxos frente à sua efemeridade e à resistência das rochas cristalinas. A textura do leito no trecho terminal do riacho dos Ferreiros é areno-cascalhosa, com predomínio de areia grossa e cascalho fino (tabela 2). Unidades morfológicas em forma de barras (figura 7) ocorrem no meio do canal (central bars) e às margens (lateral bars).

As barras, em geral, refletem o caráter episódico de fluxos no leito do canal de drenagem, armazenando o material por eles transportado (HASSAN, 2005), podendo ser modificadas a cada episódio de inundação. Mesmo pulsos de fluxo com intensidade moderada podem trazer uma mudança morfológica reconhecível nas barras (LARONNE e DUNCAN, 1992). As barras centrais, no trecho analisado, apresentaram formato alongado (figura 7), com altura aproximada de $9 \mathrm{~cm}$ com relação ao leito, compostas por cascalhos (tabela 2). Com a divergência do fluxo ao redor da fração grosseira, a competência para transportar sedimentos é reduzida e os materiais são depositados no meio do canal (BRIERLEY e FRYIRS, 2005). A formação de barras centrais sugere baixa estabilidade do fluxo, geralmente em pulsos (HASSAN et al., 2009; STORZ-PERETZ e LARRONE, 2013), com sedimentos transportados essencialmente por carga de fundo, semelhante aos canais entrelaçados (braided channels).

As barras laterais foram identificadas na margem esquerda do canal, adjacente ao talvegue (figura 7). São barras estreitas e ligeiramente alongadas, compostas por areias, especialmente areia grossa, e cascalho (tabela 2). A linha de incisão do talvegue é rasa e linear, ligeiramente sinuosa e côncava. As barras laterais são unidades que ocorrem no leito; contudo, são formas anexadas às margens de canais relativamente retilíneos (BRIERLEY e FRYIRS, 2005), como no caso analisado, e podem resultar de acréscimos laterais ou de migrações do talvegue a jusante (STORZ-PERETZ e LARRONE, 2018). Os longos períodos de recessão do fluxo de inundação no canal contribuem para a elevada concentração de material grosseiro no talvegue (tabela 2), em comparação às barras adjacentes (STORZ-PERETZ et al., 2016), devido ao tempo insuficiente para remover esses sedimentos e formar um leito mais grosseiro.

Imediatamente após as barras centrais, foi identificada uma ruptura de declive suave, transversal ao canal, na confluência com o riacho da Cruz (figura 7). A ruptura é formada por exposições do substrato em forma de soleira, definindo o nível de base local do riacho dos Ferreiros. A partir da ruptura, os sedimentos transportados pelo canal se espraiam formando lobo deposicional, ao qual denominou-se leque de desague. O leque apresentou perfil suavemente convexo, composto predominantemente por uma camada delgada de material cascalho-arenoso (tabela 2). 
Morfologias Fluviais em Ambiente Semiárido: Questões Teóricas Aplicadas a um Estudo de Caso

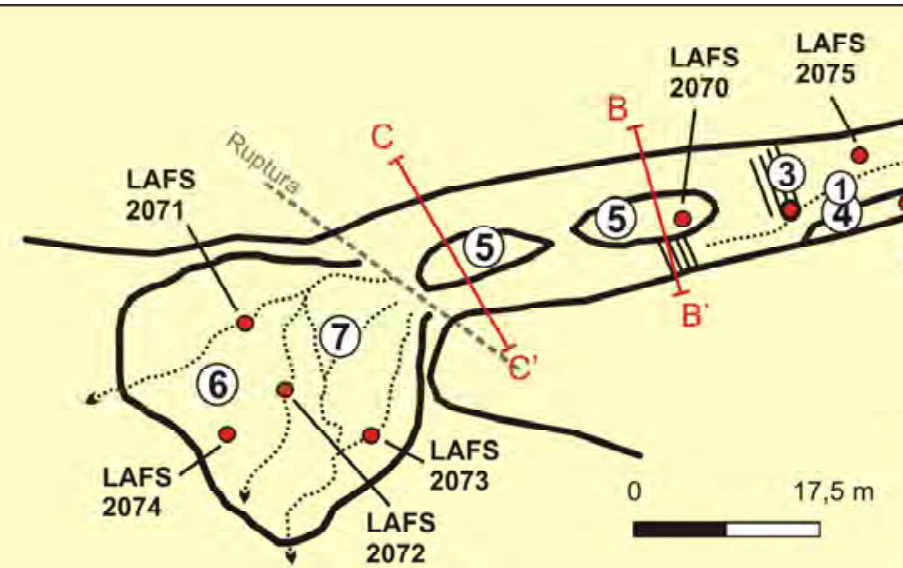

Unidades morfológicas:

1 - Leito 2 - Talvegue 3 - Soleira 4 - Barra lateral 5 - Barra central 6 - Leque de desague 7 - Microcanais

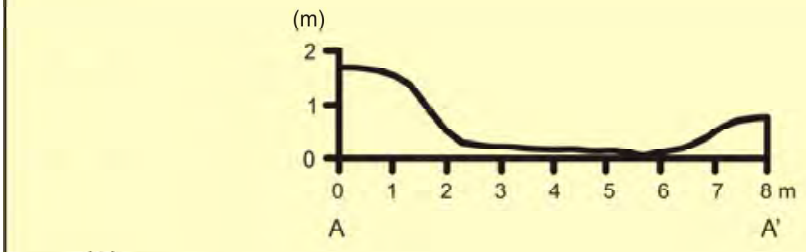

(m)
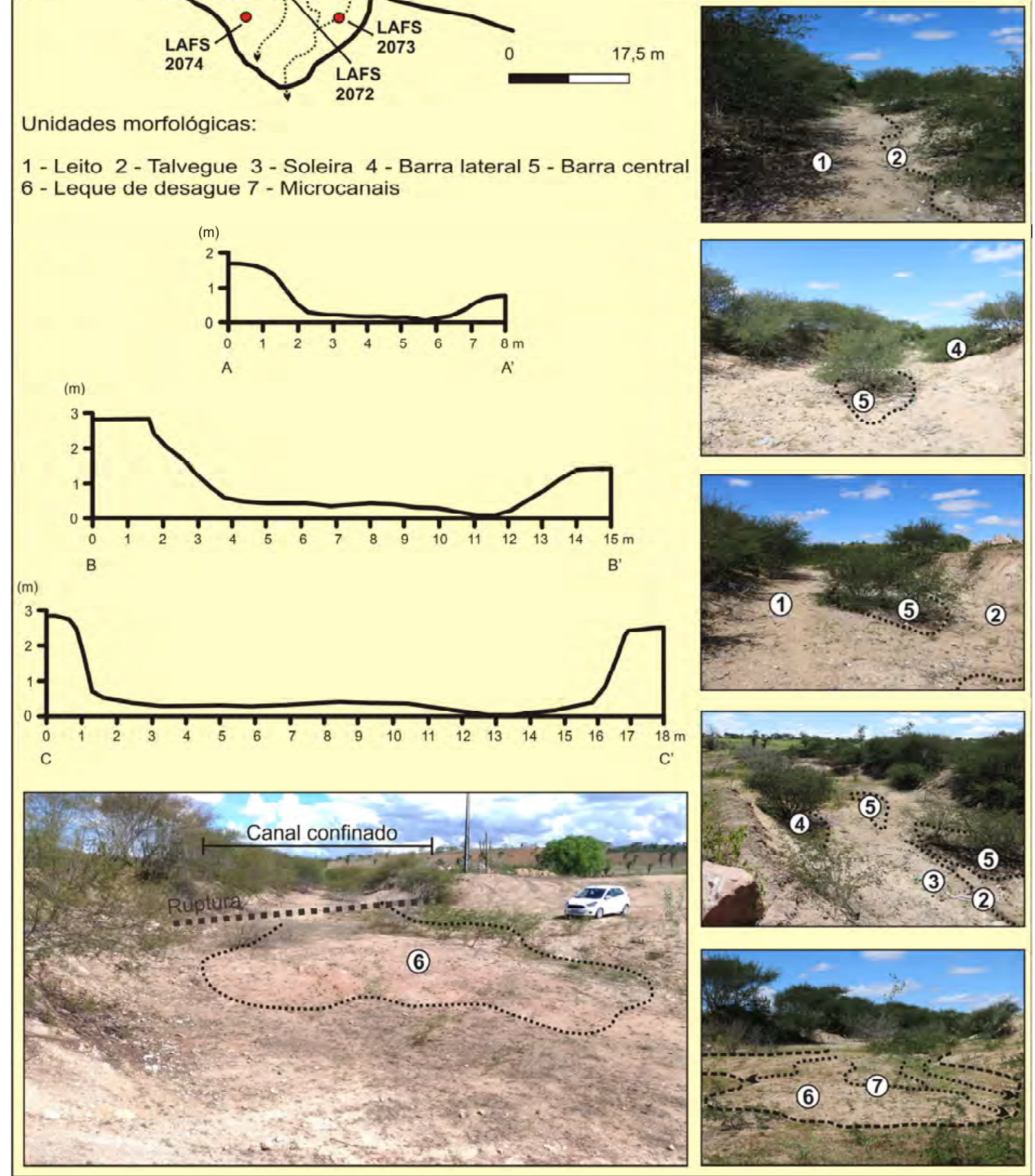

Figura 7 -Seção analítica situada na confluência do riacho dos Ferreiros com o riacho da Cruz, onde observa-se as unidades morfológicas no leito, os perfis transversais e o leque de desague. 
Tabela 2: Classes e frações granulométricas das amostras de sedimentos em seção analítica situada na confluência do riacho dos Ferreiros com o riacho da Cruz.

\begin{tabular}{ccccccccccc}
\hline \multicolumn{1}{c}{ Cascalho (\%) } & \multicolumn{3}{c}{ Areia (\%) } & \multicolumn{3}{c}{ Lama (\%) } & \\
\cline { 1 - 1 } $\begin{array}{c}\text { Cód. } \\
\text { Amostra }\end{array}$ & $\begin{array}{c}\text { Contexto da } \\
\text { Amostra }\end{array}$ & Fino & $\begin{array}{c}\text { Muito } \\
\text { Fino }\end{array}$ & $\begin{array}{c}\text { Muito } \\
\text { Grossa }\end{array}$ & Grossa & Média & Fina & $\begin{array}{c}\text { Muito } \\
\text { Fina }\end{array}$ & Silte & Argila \\
\hline $\begin{array}{c}\text { LAFS } \\
2069\end{array}$ & Barra lateral & 10,41 & 19,40 & 12,04 & 36,66 & 12,94 & 5,23 & 2,29 & 0,86 & 0,16 \\
\hline $\begin{array}{c}\text { LAFS } \\
2070\end{array}$ & Barra central & 45,46 & 15,91 & 6,21 & 13,37 & 7,04 & 6,40 & 4,02 & 1,50 & 0,10 \\
\hline $\begin{array}{c}\text { LAFS } \\
2071\end{array}$ & $\begin{array}{c}\text { Incisão } \\
\text { esquerda }\end{array}$ & 31,07 & 23,80 & 4,03 & 12,70 & 9,10 & 9,59 & 6,92 & 2,63 & 0,14 \\
\hline $\begin{array}{c}\text { LAFS } \\
2072\end{array}$ & Incisão central & 13,88 & 18,41 & 7,68 & 35,73 & 13,12 & 6,51 & 2,99 & 1,52 & 0,15 \\
\hline $\begin{array}{c}\text { LAFS } \\
2073\end{array}$ & Incisão direita & 46,88 & 17,96 & 3,38 & 6,29 & 8,59 & 6,45 & 6,83 & 3,45 & 0,15 \\
\hline $\begin{array}{c}\text { LAFS } \\
2074\end{array}$ & Leque & 29,49 & 21,75 & 6,66 & 11,37 & 8,59 & 11,89 & 7,51 & 0,31 & 0,15 \\
\hline $\begin{array}{c}\text { LAFS } \\
2075\end{array}$ & Leito & 14,51 & 16,08 & 6,70 & 16,80 & 14,00 & 16,70 & 12,17 & 0,13 & 0,13 \\
\hline
\end{tabular}

Sobre o leque, desenvolveu-se um sistema de incisões pouco profundas, a partir da linha de ruptura (figura 7). A esse conjunto de incisões interligadas entre si, empregou-se o termo sistema multicanais, cuja função é erodir o leque e transportar sedimentos em condições de fluxo de menor intensidade. Amostras de sedimentos demonstraram a variação granulométrica do material presente em três incisões (figura 7 e tabela 2) do leque de desague do riacho dos Ferreiros. Acredita-se que o cascalho corresponde ao material desagregado do substrato, exposto nas incisões por remoção do material do leque. Os sedimentos finos, provavelmente, são aqueles transportados quando da ocorrência de fluxos hídricos. Possuem maior representatividade, comparativamente, na incisão direita (tabela 2), já que esta possui maior conectividade com o talvegue, anterior à ruptura de declive (figura 7).

$\mathrm{Na}$ literatura geomorfológica, existem poucas referências a feições em leque situadas na confluência entre canais de drenagem efêmeros. O termo terminal fan - leque terminal - foi definido por Kelly e Olsen (1993) como um sistema fluvial cuja drenagem é totalmente dissipada internamente por meio de uma rede de escoamento distributiva, sem que haja perdas para um lago ou mar em condições normais. Leques terminais ocorrem onde os fluxos, carregados de sedimentos, diminuem de tamanho e desaparecem como resultado das perdas por evaporação (ABDULLATIF, 1989; TOOTH, 2000). Eles tendem a se formar em regiões áridas ou semiáridas devido ao déficit de umidade (BILLI, 2007; BILLI, 2008), sendo considerados sistemas de drenagem endorréicos. Nesse caso, as feições em leque estão posicionadas no trecho final de todo o sistema de drenagem. Assim, a terminologia torna-se inadequada para o contexto dessa pesquisa, pois o leque do riacho dos Ferreiros posiciona-se em área de confluência, em oposição aos leques terminais.

$\mathrm{Na}$ bibliografia norte-americana, Vyverberg (2010) utilizou o termo channel fan (leque de canal) para definir acumulações aluviais em forma de leque, resultantes da perda do fluxo hídrico a jusante e do declínio na capacidade de transporte de sedimentos. Diferente de floodout e de sheetflood zones, channel fan se distingue, a priori, das primeiras, pois ocorrem espacialmente na confluência entre canais, sobre o leito ou planície aluvial do canal de maior dimensão. Na literatura brasileira, Azambuja (2012) identificou depósitos semelhantes na confluência entre canais de drenagem efêmeros do semiárido de Pernambuco, formados pelo extravasamento da carga arenosa, resultante do rompimento de pequenos barramentos. Contudo, o termo utilizado pelo autor, depósito lobado, não faz referência à forma, mas apenas à sua composição. 


\section{Morfologias Fluviais em Ambiente Semiárido: Questões Teóricas Aplicadas a um Estudo de Caso}

Embora a expressão leque de canal, da tradução channel fan, seja a que possui as características mais próximas do leque de desague, optou-se por atribuir o emprego dessa terminologia para os leques elaborados em descontinuidades de canal, conforme discussões anteriores. Levando-se em consideração que a zona de confluência entre canais são áreas onde ocorre o desague de fluxos hídricos quando da sua ocorrência, considera-se pertinente o emprego do termo leque de desague, no sentido de diferenciá-los dos leques de canal.

Define-se então, leque de desague como forma de origem fluvial com aspecto espraiado, situado em confluências entre canais. Sua gênese está associada a descargas esporádicas de fluxos e sedimentos grosseiros, em confluências com desníveis topográficos suaves entre o canal de maior hierarquia e o afluente de menor ordem. A baixa frequência e a diminuição da magnitude e velocidade do fluxo a jusante do canal contribuem com a perda da capacidade de transporte da carga e consequente espraiamento. Sobre os leques desenvolvem-se sistemas multicanais em rede, responsáveis por dissecarem os leques ao transportarem sedimentos em condições de fluxos de magnitude inferior.

No contexto regional é comum a ocorrência de leques de desague situados na confluência entre canais de drenagem. Para fins comparativos, foram identificados leques em bacias hidrográficas próximas a área de estudo, de diferentes dimensões espaciais, com características litológicas, topográficas e climáticas semelhantes (figura 8). Por meio das imagens é possível observar o espraiamento dos sedimentos sobre planícies aluviais, onde as diferentes dimensões podem expressar diferentes graus de desenvolvimento dos leques.
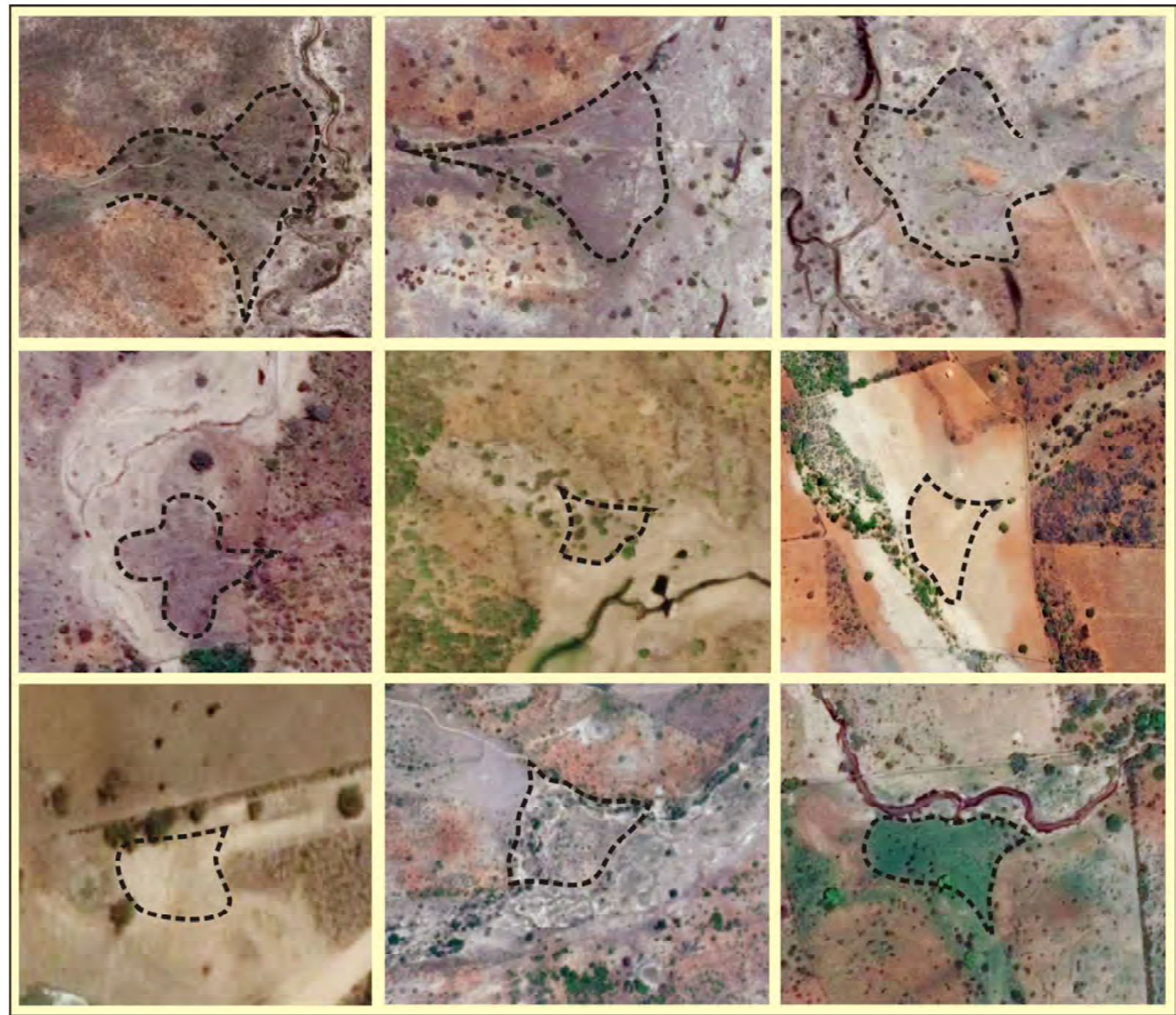

Figura 8-Leques de desgaue de dimensões variadas, situados em confluências de canais de drenagem de bacias hidrográficas localizadas próximas a bacia do riacho da Cruz. 


\section{Conclusões}

A bibliografia geomorfológica internacional produziu, ao longo de décadas de pesquisa, um vasto conhecimento a respeito das dinâmicas e processos de formação do relevo em ambientes secos que permitiram o desenvolvimento de teorias, conceitos e terminologias, próprias para esse tipo de ambiente. Apesar disso, diversos autores apontam a necessidade de se avançar no conhecimento das regiões secas, em comparação aos ambientes úmidos, mesmo diante de dificuldades em se pesquisar aspectos da dinâmica fluvial regiões com elevada deficiência hídrica.

No contexto brasileiro, os avanços ainda se referem ao campo da pesquisa geomorfológica básica onde, acredita-se, a aproximação com a produção internacional é uma das formas de se produzir conhecimento sobre o semiárido. Entretanto, com base nessa pesquisa, defende-se que o emprego de termos geomorfológicos da literatura internacional ao contexto nacional deve ser realizado com cautela, fazendo-se as adaptações necessárias, principalmente devido a questões de tradução. Também, deve-se considerar que se trata de um ambiente quente e seco localizado em baixas latitudes, cujos fenômenos climáticos equatoriais (Zona de Convergência Intertropical, p.ex.), podem, eventualmente, atuar de maneira significativa sobre o relevo regional, especialmente no setor setentrional do semiárido.

Ressalta-se também que a utilização de termos desenvolvidos em contextos úmidos, como feito tradicionalmente na literatura nacional, não é adequada para o semiárido, o que pode levar a uma interpretação equivocada sobre a morfodinâmica regional. Diante disso, aponta-se a necessidade de desenvolvimento de pesquisas que contribuam com a produção de dados primários e com análises mais complexas de processos atuantes em diferentes escalas de análise. Estudos de caso em diferentes cenários do semiárido podem contribuir com a sistematização de conceitos e o desenvolvimento de teorias próprias que expressem o caráter dinâmico de formação do relevo nesse ambiente.

\section{Agradecimentos}

Agradecemos à Coordenação de Aperfeiçoamento de Pessoal de Nível Superior (CAPES) pela concessão de bolsa de estágio pós-doutoral (processo $n^{\circ}$ 88882.317847/2019-01); e ao Prof. Dr. Jémisson
Mattos dos Santos e equipe do Laboratório da Dinâmica e Gestão do Ambiente Tropical (Geotrópicos), da Universidade Estadual de Feira de Santana, pelo suporte nos trabalhos de campo. Agradecemos ainda aos pareceristas anônimos pelas observações e considerações referentes ao manuscrito.

\section{Referências Bibliográficas}

ABDULLATIF, O.M. Channel-fill and sheet-flood facies sequences in the ephemeral terminal River Gash, Kassala, Sudan. Sedimentary Geology, v. 63, n. 1-2, p. 171-184, 1989. DOI: 10.1016/0037-0738(89)90077-8

ANDRADE, J.H.R.; MAIA, C.E. Erosão de Margens em Rios Semiáridos: Estudo na Sub-Bacia do Baixo Jaguaribe - Ceará - Brasil. Revista Brasileira de Geomorfologia, v.19, n.4, p.859870, 2018. DOI: 10.20502/rbg.v19i4.1379

AZAMBUJA, R.N. Dinâmica superficial em uma bacia de drenagem semiárida: um estudo de caso da bacia do riacho Salgado-PE. Tese (Doutorado em Geografia). Centro de Filosofia e Ciências Humanas, Universidade Federal de Pernambuco, Recife. 2012. 247 p.

BILLI, P. Morphology and sediment dynamics of ephemeral stream terminal distributary systems in the Kobo Basin (northern Welo, Ethiopia). Geomorphology, 85, p. 98-113, 2007. DOI: 10.1016/j.geomorph.2006.03.012

BILLI, P. Bedforms and sediment transport processes in the ephemeral streams of Kobo basin, northern Ethiopia. Catena, 75, p. 5-17, 2008. DOI: 10.1016/j.catena.2008.04.002

BRIERLEY, G.J.; FRYIRS, K.A. Geomorphology and river management: applications of the river styles framework. Blackwell Publishing, 2005. 398 p.

BULL, W.B. Discontinuous ephemeral streams. Geomorphology, 19, p. 227-276, 1997. DOI: 10.1016/S0169-555X(97)00016-0

CAMARGO, O.A.; MONIZ, A.C.; JORGE, J.A.; VALADARES, J.M. Métodos de análise química, mineralógica e física de solos do Instituto Agronômico de Campinas. Campinas: Instituto Agronômico de Campinas, 1986. 94 p.

CANTALICE, J.R.B.; CUNHA FILHO, M.; STOSIC, B.D.; PISCOYA, V.C.; GUERRA, S.M.S.; SINGH, V.P. Relationship between bedload and suspended sediment in the sand-bed Exu River, in the semi-arid region of Brazil. Hydrological Science Journal, v. 58, n. 8, p. 1789-1802, 2013. DOI: $10.1080 / 02626667.2013 .839875$ 
CAVALCANTE, A.A. Geomorfologia fluvial no semiárido brasileiro. Revista de Geografia (Recife), v. 35, n. 4, p. 254$268,2018$.

CHRISTOFOLETTI, A. Geomorfologia. Segunda edição. São Paulo: Edgard Blücher, 1980. 188 p.

CORRÊA, A.C.B. Antropogênese e morfogênese sob a ação de eventos climáticos de alta magnitude no semiárido pernambucano: o caso da bacia do riacho do salgado. Revista Brasileira de Geomorfologia, v. 12, n. 3, p. 25-36, 2011. DOI: 10.20502/rbg.v12i0.256

FIELD, J. Channel avulsion on alluvial fans in southern Arizona. Geomorphology, 37, p. 93-104, 2001. DOI: 10.1016/S0169$555 \mathrm{X}(00) 00064-7$

FIELD, J.; LICHVAR, R.W. Review and Synopsis of Natural and Human Controls on Fluvial Channel Processes in the Arid West. Hanover, NH: United State Army Engineer Research and Development Center, 2007. 56 p.

GORE, D.; BRIELEY, G.; PICKARD, J.; JANSEN, J. Anatomy of a floodout in semi-arid eastern Australia. Zeitschrift für Geomorphologie, suppl.-Bd, 122, p. 113-139, 2000.

GOUDIE, A. S. Arid and semi-arid geomorphology. New York: Cambridge University Press, 2013. 454 p.

GRAF, W.L. Fluvial processes in Dryland Rivers. Berlin: Spring-Verlag, 1988. 346 p.

GUERRA, A.T.; GUERRA, A.J.T. Novo dicionário geológicogeomorfológico. Nona edição. Rio de Janeiro: Bertrand Brasil, 2011. $648 \mathrm{p}$.

HASSAN, M.A. Characteristics of gravel bars in ephemeral streams. Journal of Sedimentary Research, v. 75, n. 1, p. 2942, 2005. DOI: $10.2110 /$ jsr.2005.004

HASSAN, M.A.; MARREN, P.M.; SCHWARTZ, U. Bar structure in an arid ephemeral stream. Sedimentary Geology, 221, p. 57-70, 2009. DOI: 10.1016/j.sedgeo.2009.07.012

INSTITUTO BRASILEIRO DE GEOGRAFIA E ESTATISTICA (IBGE). Manual Técnico de Geomorfologia. Segunda Edição. Rio de Janeiro: IBGE, Coordenação de Recursos Naturais e Estudos Ambientais, 2009.

KELLY, S.B.; OLSEN, H. Terminal fans - a review with reference to Devonian examples. Sedimentary Geology, 85, p. 339-374, 1993. DOI: 10.1016/0037-0738(93)90092-J

LARONNE, J.B.; DUNCAN, M.J. (1992). Bedload transport paths and gravel bar formation. In BILLI, P.; HEY, R.; THORNE, C.; TACCONI, P. (Eds.) Dynamics of gravel-bed rivers. Wiley,
Chichester: p. 177-202.

LIMA, K.C.; CUNHA, C.M.L. Atualização Cartográfica da rede de drenagem para estudo geomorfológico de rios intermitentes e efêmeros no semiárido. Revista Brasileira de Cartografia, v. 66, n. 1, p. $127-136,2014$

PATTON, P.C.; SCHUMM, S.A. Gully Erosion, Northwestern Colorado: A Threshold Phenomenon. Geological Society of America Bulletin, 8, p. 88-90, 1975.

DOI: 10.1130/0091-7613(1975)3<88:GENCAT>2.0.CO;2

SCHUMM, S.A.; HADLEY, R.F. Arroyos and the semiarid cycle of erosion. American Journal of Science, v. 255, n. 3, p. 161-174, 1957. DOI:10.2475/ajs.255.3.161

SERVIÇO GEOLÓGICO DO BRASIL (CPRM). Programa levantamentos geológicos básicos do Brasil. Carta geológicaEscala 1: 250.000 (Folha Serrinha SC.24-Y-D). 1989. Disponível em <www.cprm.br/geobank>. Acesso em 19 de abril de 2018.

SOUZA, J.O.P.; ALMEIDA, J.D.M. Processos fluviais em terras secas: uma revisão. Revista OKARA: Geografia em debate, v.9, n.1, p. 108-122, 2015.

STEVAUX, J.C.; LATRUBESSE, E.M. Geomorfologia fluvial. São Paulo: Oficina de Textos, 2017. 336 p.

STORZ-PERETZ, Y.; LARONNE, J.B. Morphotextural characterization of dryland braided channels. Geological Society of America Bulletin, v. 125, n. 9/10, p. 1599-1617, 2013.

DOI: $10.1130 / \mathrm{B} 30773.1$

STORZ-PERETZ, Y.; LARONNE, J. B.; SURIAN, N.; LUCÍA, A. Flow recession as a driver of the morpho-texture of braided streams. Earth Surface Processes and Landforms, 41, p. 754-770, 2016. DOI: 10.1002/esp.3861

STORZ-PERETZ, Y.; LARONNE, J.B. The morpho-textural signature of large bedforms in ephemeral gravel-bed channels of various planforms. Hydrological Processes, 32, p. 617-635, 2018. DOI: 10.1002/hyp.11437

SUPERINTENDÊNCIA DE ESTUDOS ECONÔMICOS E SOCIAIS DA BAHIA (SEI). Balanço hídrico do estado da Bahia. Salvador: SEI, 1999.

TOOTH, S. (1999). Floodouts in central Australia. In MILLER, A.; GUPTA, A. (Eds.) Varieties of Fluvial Form. Wiley, Chichester: p. 219-247.

TOOTH, S. Process, form and change in dryland rivers: a review of recent research. Earth-Science Reviews, 51, p. 67-107, 2000. DOI: $10.1016 / \mathrm{S} 0012-8252(00) 00014-3$ 
Lima K. C. \& Lupinacci C. M.

TOOTH, S.; NANSON, G.C. (2011). Distinctiveness and Diversity of Arid Zone River Systems. In THOMAS, D.S.G. (Ed.) Arid Zone Geomorphology: Processes, Form and Change in Drylands (3nd. ed.). Wiley-Blackwell, Chichester: p. 269-300.

TOOTH, S.; MC CARTHY, T.; RODNIGHT, H.; KEEN-ZEBERT, A.; ROWBERRY, M.; BRANDT, D. Late Holocene development of a major fluvial discontinuity in floodplain wetlands of the Blood River, eastern South Africa. Geomorphology, 215, p.
128-141, 2014. DOI: 10.1016/j.geomorph.2011.12.045

TRICART, J. Pinciples et méthodes de la géomorphologie. Paris: Masson, 1965. 496 p.

VERSTAPPEN, H.T.; ZUIDAM, R.A.V. ITC System of geomorphological survey. 3nd. ed. Enschede: ITC, 1975, Vol. VII. $52 \mathrm{p}$.

VYVERBERG, K. A review of stream processes and forms in dryland watersheds. Sacramento: California Department of Fish and Game, 2010. 32 p. 